\title{
O plano de desenvolvimento local no Tucunduba: uma experiência de gestão urbana reformista na Amazônia
}

Charles Benedito Gemaque Souza - Doutorando pelo Núcleo de Altos Estudos Amazônicos - NAEA.

\section{Resumo}

Este trabalho examina o Plano de Desenvolvimento Local (PDL) para a ocupação urbana do Riacho Doce (20012004) na bacia do Tucunduba em Belém, a partir da concepção do documento, da percepção da equipe técnica e das vivências dos moradores. Deste modo, analisa as referências e as discussões em torno de um novo projeto de democratização da cidade, baseado no ideário da Reforma Urbana. Trata-se, portanto, de uma tentativa de retomar a teoria do espaço social por meio da contextualização do planejamento urbano na Amazônia e, designadamente, com as contradições sócio-espaciais presentes na trajetória das políticas públicas em Belém, criando um exercício de reconhecimento e de apreensão da complexidade da cidade, assim como propor novas possibilidades de gestão urbana.

\section{Abstract}

This work examines the Local Development Plan (LDP) for the urban occupation of "Riacho Doce" (2001-2004), in the Tucunduba basin, in the city of Belém, based on the document conception, the perceptions of the technical team, and the experiences of the dwellers. It analyzes references and discussions regarding a new project for the city re-democratization, based on the ideals of Urban Reform. The work is, therefore, an attempt to reexamine the social space theory through the contextualization of urban planning in the Amazon region, at pace with social and spatial contradictions in urban policies for the city of Belém. It is an exercise of recognition and acknowledgement of the city complexities, as well as a proposal for new possibilities of urban management.

\section{Palavras-chave}

Desenvolvimento local; ocupação urbana; espaço social.

\section{Keywords}

Local development; urban occupation; social space. 


\section{INTRODUÇÃO}

A produção social do espaço traduz o processo histórico de ocupação e de estruturação de cada lugar, uma vez que o ambiente, sua trajetória e suas representações são fundamentais para a construção de uma racionalidade cotidiana em cada grupo de indivíduos.

O espaço urbano caracteriza-se pela ação contínua do poder público, que acaba muitas vezes impondo uma racionalidade global de mercado, por meio da (re) estruturação do cotidiano previamente estabelecido. Instauram-se sistemas de objetos e de ações oriundos de realidades sociais e espaciais distintas, como as encontradas na Amazônia, que não apenas modificam a paisagem das cidades, como lhe impõem um estilo de vida estranho, burocrático, competitivo e individualista ao seu morador.

Os lugares acolhem e usufruem as ações concebidas pela racionalidade hegemônica, mas, ao mesmo tempo, permitem o surgimento de uma contra-racionalidade ligada às experiências de vida dos seus moradores. Nesse sentido, os moradores são a redefinição do mundo a partir das individualidades, das especificidades e das diversidades presentes, ou seja, são manifestações da totalidade-mundo, da qual são "esquizofrenias espaciais". (SANTOS, 2002, p. 68).

Considerando isso, a administração municipal de Belém (19972004) buscou construir um plano de desenvolvimento local de inspiração reformista, que superasse as distorções sociais e, por conseqüência, as espaciais, com base em uma concepção que não se levasse em conta apenas o viés econômico da idéia de desenvolvimento. Tal proposta foi concretizada com a participação dos agentes sociais envolvidos, incluindo os moradores, nas diversas fases do projeto, como forma de viabilizar os anseios e as demandas reais das famílias atingidas.

\section{$1 \mathrm{O}$ desenvolvimento local em relação ás políticas urbanas emergentes}

Dada a crescente rivalidade em termos globais, a idéia de desenvolvimento local representa uma possibilidade de dinamizar potenciais endógenos, incorporando à tradicional concepção de desenvolvimento instrumentos inovadores e supostamente democráticos, como a participação dos moradores atingidos.

Quando se trata de uma cidade, desenvolvimento local ganha uma configuração espacial concreta: o espaço urbano. Isso permite uma análise comparativa de diversos modelos de desenvolvimento localurbano, seus instrumentos, objetivos, fenômenos e os atores envolvidos.

O desenvolvimento local-urbano encerra um emaranhado de fenômenos implícitos e determinantes para sua aplicação, que variam de acordo com a origem política ou a classe do gestor público municipal. Desse modo, os objetivos e as diretrizes a que se propõe em seus aspectos teóricos trazem uma teia de políticas de desenvolvimento localurbano, distintas e, ao mesmo tempo, ligadas.

Os principais estratagemas do desenvolvimento local explicitamente 
competitivo, por exemplo, são o pragmatismo técnico e a criação de imagens positivas (FREY, 1996). O espaço urbano torna-se uma mercadoria que utiliza constantes inovações infra-estruturais e uma consistente política de propaganda, com o intuito de atrair velhos e novos consumidores.

Curitiba, no Estado do Paraná, representa perfeitamente esse denominado "urbanismo espetáculo" (SANCHES, 1999, p.15) subsidiado por uma oportunista e eficiente máquina de propaganda. Assim, Curitiba intitulou-se a "cidade modelo", a "cidade ecológica", a "cidade do futuro", enfim, a cidade vende uma imagem de vanguarda, atenta aos grandes dilemas modernos. É o chamado city marketing.

Seguindo a tradição de Weber, o quadro técnico obedece a uma rígida hierarquização e a uma fragmentação das competências, havendo uma negociação direta e amigável com a iniciativa privada, enquanto o Legislativo é submetido ao poder do "decretismo". Nesse modelo de desenvolvimento local competitivo, a participação da sociedade é muitas vezes contemplativa, apenas conveniente para legitimar a administração municipal.

Existem casos em que se efetiva essa participação na fase de implementação de alguns projetos, mas de forma casual. FREY (1996) acrescenta que essa participação requer uma relação emotiva entre a população e a cidade, criando uma identidade imposta a partir de uma massificação de imagens positivas. A relação de confiança e a impressão de consenso em torno da política urbana edificam, entre os moradores, um contentamento coletivo.

Os projetos engenhosos e grandiosos são priorizados, de preferência em pontos centrais da cidade, dando ao projeto um aspecto visível e simbólico. O lançamento da obra é cercado de novidade e apresentado como um instrumento coletivo, fruto de um consenso sem diálogo (SANCHES, 1999). Institui-se, assim, uma atmosfera de otimismo e harmonia, que viabiliza investimentos e assegura a continuidade política.

A cidade torna-se abstrata, ilusória, um espetáculo para os visitantes, enquanto seus moradores, envaidecidos, contemplam e glorificam seus administradores. Em contrapartida, as noções de solidariedade e de participação são solapadas, impedindo-se uma possível conscientização política, escamoteando-se conflitos de interesses inerentes ao espaço urbano. Tal despolitização do espaço social só beneficia determinados grupos, em detrimento da sociedade em geral.

Ademais, o desenvolvimento local competitivo adota uma abordagem isolacionista e individualista, o que acaba aprofundando as disparidades entre as localidades, aumentando a fragmentação territorial e a reificação do espaço.

Em suma, o desenvolvimento local competitivo tem a mesma matriz teórica da economia neoclássica, traduzida na racionalidade instrumental, nas vantagens comparativas e no individualismo das 
ações, aliados à participação e à gestão local, porém as duas últimas de forma reduzida (BRAGA, 1999).

Outra proposta de desenvolvimento local-urbano é o denominado desenvolvimento local integrado e sustentável (DLIS). Fundamentado no conceito de situacional elaborado por MATUS (1989), combina o conceito de desenvolvimento local com o de integração e de inovação dos atores sociais envolvidos e o de sustentabilidade ambiental, econômica e institucional.

De acordo com o autor acima citado, a situação não se limita a uma apreciação do presente, mas conota o futuro e explica o passado. Dessa forma, qualquer idealização passa pelo entendimento e pela articulação do contexto situacional, ou seja, está ligada à capacidade de se chegar à situação esperada a partir de um processo teleológico. O próprio MATUS (1989) resalta, porém, que previsões situacionais não devem ser confundidas com predições de resultados, mesmo porque a capacidade de antecipar possíveis desvios é inerente às políticas públicas.

O princípio da sustentabilidade, no DLIS, está relacionado com a máxima de que se deve produzir mais e melhor, com equidade na distribuição das riquezas e sem inviabilizar as gerações futuras. No entanto, sustentável diz respeito também, e principalmente, a um padrão de organização de um sistema que se mantém ao longo do tempo por ter adquirido certas características que lhe conferem "um padrão de organização em rede dotado de características como interdependência, reciclagem, parceria, flexibilidade e diversidade" (FRANCO, 2000, p. 23).

Percebe-se que há uma grande aposta na habilidade inovadora, técnica e política dos agentes sociais envolvidos, porém a idéia de consenso prevalece. Os conflitos de interesses seriam negociados entre os diversos atores envolvidos em busca de um pensamento único, maduro e conciliador, arquétipo da filosofia de vida de Gandhi, mediado por um dos agentes.

As potencialidades de cada local são inventariadas por meio de um diagnóstico consensual feito pelos agentes sociais envolvidos, indicando-se possíveis vetores humanos, culturais e naturais para o desenvolvimento, de acordo com as condições favoráveis e viáveis, isto é, de acordo com a situação do local. Estabelece-se uma dinâmica sistêmica fechada, susceptível de constante realimentação; por isso, o capital social local é imprescindível (FRANCO, 2000).

Trata-se de um modelo de desenvolvimento urbano/local que envolve interações e processos acumulativos de aprendizagem dos agentes inovadores, em busca de uma competitividade maior do local no contexto global. Nesse caso, o DLIS relaciona-se com as idéias da teoria evolucionária em economia.

Os propósitos do DLIS são difíceis de operacionalizar dada complexidade urbana. A escolha dos atores sociais é premissa de uma instituição que necessita de idoneidade e de competência indiscutíveis,

104 
porém, considerando que o Estado não pode estar acima do bem e do mal, como garantir que essa instituição não está criando uma fachada democrática para legitimar os seus interesses particulares? Até porque, essa instituição necessariamente delega a si mesma o papel de mediadora do debate, o que, amiúde, significa que o consenso estará direta ou indiretamente a cargo dessa instituição.

A própria idéia de consenso é, no mínimo, estranha em áreas de intensos conflitos de interesses, como é o caso do espaço urbano. Há, freqüentemente, por trás da noção de consenso, ainda que a participação popular seja efetivada, o favorecimento do grupo social que está à frente do poder político. Isso expurga o conflito do campo de análise, não dando margem à negociação, por outro lado, destoa da realidade cotidiana dos espaços urbanos brasileiros, reconhecidamente heterogêneos, dificultando a própria escolha do público-alvo do desenvolvimento local (BRAGA, 1999).

A carência de capital social torna-se um empecilho sério para a implementação do DLIS no espaço urbano, uma vez que dificulta a acumulação de ações empreendedoras. Isso significa dizer que é improvável que a população urbana envolva-se espontaneamente, apenas pelo fato de se criar um instrumento participativo, como afirma FRANCO (2000). Além disso, o "imediatismo" próprio das políticas públicas urbanas, tanto dos técnicos na ânsia de "mostrar serviço", quanto da população alvo em relação aos resultados concretos, atropela o desencadeamento espontâneo da construção de uma conscientização política entre os moradores, restringindo-a às lideranças comunitárias ou a um grupo político.

Entretanto, a participação dos moradores deve, sem dúvida, ser o caminho mais indicado para se construir um governo local democrático, limitando equívocos e, acima de tudo, invertendo prioridades no tocante às políticas de investimentos urbanos. Nesse caso, são necessarios ações que relacionem o fortalecimento da consciência política dos moradores, objetivo de longo prazo, com projetos palpáveis e atrativos com menores prazos de duração.

Considerando esses argumentos, BRAGA (1999) propõe um desenvolvimento local solidário, a partir do fortalecimento dos mecanismos de participação e de gestão urbana, e, ao mesmo tempo, sistêmico, com uma maior integração do local com o contexto global.

Nesse intuito, a autora destaca alguns elementos. Primeiro, indica a necessidade de negociação entre os atores sem negar os conflitos de interesses e a assimetria de poder entre eles. O objetivo dessa negociação é criar um pacto de desenvolvimento, deixando claro quais interesses seriam mais ou menos favorecidos. Outro elemento é a recuperação das noções de solidariedade e de cidadania para todos, o que, para a autora, implica necessariamente a cooperação entre as localidades e destas com a federação.

Entretanto, a própria BRAGA (1999) mostra um ceticismo em 
relação às teorias de desenvolvimento local, considerando uma ilusão vender a idéia de desenvolvimento micro diante de um mundo dominado por grandes corporações transnacionais. Para a autora, essa idéia só contribui para manter as lógicas individualistas e de mercado. Por sua vez, a incumbência de se potencializar as vantagens locais para dinamizar a economia faz que esses objetivos tornem-se um "interesse coletivo" da sociedade local, em detrimento do fortalecimento da cidadania a partir da valorização dos espaços socialmente construídos.

\section{O PDL como consolidação de uma proposta reformista}

O Plano de Desenvolvimento Local (PDL) foi uma ação prevista pela Prefeitura Municipal de Belém (PMB), no âmbito do Projeto de Recuperação e Urbanização da Bacia do Tucunduba (PRUBT), embora sua execução esteja especificamente voltada para as ocupações do Riacho Doce e do Pantanal, ao sudoeste de Belém.

Trata-se de um plano que abrange não somente as obras físicas, mas também projetos socio-ambientais, na tentativa de envolver a comunidade local no processo. Nesse sentido, o PDL está inserido em um cenário maior de discussões sobre uma política de desenvolvimento urbano reformista em Belém, que leve em consideração a inclusão social da população de baixa renda, sobretudo daquela que vive em assentamentos urbanos "subnormais".

O governo municipal de Belém propõe-se a operar uma ruptura com os padrões "modernistas" de desenvolvimento urbano de administrações anteriores, a partir da inversão de prioridades e por meio da implementação de mecanismos de participação e de controle social. -O desafio é "construir uma nova matriz que não siga o mesmo caminho de dominação economicista e ideológico de inspiração externa, mas a construção de uma práxis urbana comprometida com os agentes sociais produtores da cidade" (BELÉM, 2001a, p. 2).

De acordo com essa concepção, um plano de desenvolvimento local reformista poderia representar uma possibilidade real de concretização de uma política urbana voltada para a inclusão dos agentes sociais e dos diversos espaços da cidade. "A proposta do plano pretendia, assim, potencializar projetos e intervenções atuais e futuras, agindo de forma integrada, orientando ações, e transformando esta experiência em referência de co-gestão da cidade" (BELÉM, 2001a, p. 15).

Tal proposta de desenvolvimento local reformista da PMB busca uma inserção de fato da cidade "ilegal", que sempre esteve excluída das políticas urbanas em Belém, sendo, também, um mecanismo para se potencializar as forças políticas das ocupações. De acordo com essa proposta, "o governo do povo propõe realizar uma experiência de implementação de projetos de reurbanização em áreas de ocupação, através de um planejamento que consolide um modelo de co-gestão" (BELÉM, 2001 a, p. 4).

Para tanto, crê-se na aptidão da comunidade local para sustentar

106 
esse projeto alternativo, visando à mudança na matriz do desenvolvimento da cidade. Tal procedimento passava pelo entendimento de que esse processo é um exercício permanente de democracia participativa Em decorrência disso, o fortalecimento político dos moradores é um dos elementos chave dessa proposta de desenvolvimento local de Belém.

O documento final enfatiza que o grande desafio é abdicar de fórmulas viciadas, já consolidadas na relação entre os técnicos e a população atingida, na qual as diferenças são dissimuladas, produzindose uma cidade desigual e excludente.

A partir do diálogo entre os técnicos e os moradores locais, o PDL sugere que haja a absorção das possíveis representações sociais dos atores sociais locais. Dessa maneira o técnico precisará valorizar o conhecimento do "outro", assim como compartilhar o seu próprio conhecimento. Constata-se aí uma similaridade teórico-conceitual com a proposta de Matus (1989) de substituição do planejamento normativo pelo planejamento estratégico situacional.

Desse modo, as famílias atingidas e a equipe técnica atuam como sujeitos da proposta de desenvolvimento local reformista, o que transformaria as etapas de concepção, de elaboração, de implementação e de controle do PDL um exercício político de construção do poder popular, o que possibilitaria a ampliação e o fortalecimento dos instrumentos de gestão da cidade. (BELEM, 2001a). A proposta da PMB sugere uma articulação política entre os vários atores sociais envolvidos até chegarem a um consenso.

De outro lado, o fortalecimento da cidadania e da solidariedade requer, também, uma articulação com o regional e o global, além da busca da redução das desigualdades socio-espaciais no local. Por isso, o PDL propôs uma matriz inovadora de política pública na cidade que abarcaria não apenas o urbano, ou o local, mas também estaria ligada a possíveis mudanças no conjunto do País.

Pode-se dizer que o PDL assemelha-se à proposta de Braga (1999) que defende uma concepção sistêmica de desenvolvimento com base em uma interação estratégica entre as escalas micro, meso, macro e meta, na tentativa de evitar que a proposta de desenvolvimento local solidário provoque uma fragmentação das esferas do espaço.

A idéia de sustentabilidade no PDL ganha três vertentes. Em primeiro lugar, o PDL visa a "estabelecer padrões e procedimentos próprios para servirem de orientação às ações do governo municipal na implementação de programas e projetos da política urbana ambiental e de autoconsciência" (BELÉM, 2001a, p. 34).

Em segundo lugar, o PDL baseia-se na noção de sustentabilidade ambiental, que diz respeito ao não esgotamento dos recursos naturais do Riacho Doce, necessários para as gerações atuais e, imagina-se, também para as gerações futuras. Há no PDL um volume exclusivo (o terceiro), em que se faz um relatório sobre as alterações na bacia 
hidrográfica e na cobertura vegetal original do local, apresentando-se projetos de recuperação e de educação ambiental.

Existe uma relação direta entre a proposta de sustentabilidade ambiental e o urbanismo ecológico, porém o PDL não limita as necessidades humanas às amenidades ambientalistas. Em vez disso, o documento aponta parâmetros econômicos e políticos para a utilização comercial e o manejo florestal, assim como para o estabelecimento de um ponto turístico no Riacho Doce.

Em terceiro lugar, o PDL defende a sustentabilidade cultural segundo a qual é necessário resgatar "as lutas históricas e sociais na busca de conhecimento e reconhecimento das identidades culturais e sociais dos agentes sociais locais, para o fortalecimento de sua organização" (BELÉM, 2001b, p. 16). Embora não explicitada, a dimensão do espaço vivido acaba fazendo-se presente na proposta de desenvolvimento local no Riacho Doce.

Todavia, o desafio consiste em identificar como o vivido vai ser incorporado na intervenção pública. Nesse sentido, a idéia de que a "construção ou melhorias de unidades habitacionais devem respeitar as especificidades e representações simbólicas das comunidades locais" (BELÉM, 2001a, p.35) evoca a importância do espaço-casa para os moradores das ocupações urbanas de Belém, enfatizada por Costa (2002).

$\mathrm{Na}$ concepção de Costa (2002, p.74) as moradias das ocupações urbanas de Belém estão "afetadas pelas práticas culturais próprias dos locais de origem de seus moradores e podem ser reflexos do processo econômico da cidade". Por isso, seu significado, seu uso e sua funcionalidade traduzem a representação que o morador construiu durante a vida no seu local de origem, principalmente à beira-rio.

Além disso, o PDL adota a idéia de fortalecimento das estratégias de trabalho e de renda pre-existentes no cotidiano do Riacho Doce, para fomentar ações de dinamização econômica. A incorporação, nesse caso, da teoria da economia popular solidária reforça o intuito de valorizar as práticas socio-espaciais já estabelecidas na ocupação do Riacho Doce.

No PDL as experiências e as vivências assumem conotações diversas. O vivido não é explicitamente reconhecido no documento final, mas está subentendido em algumas propostas assumidas. Paradoxalmente, em algumas ponderações, a busca do embelezamento e da modernização do espaço ainda prevalece sobre a idéia de dinamizar o espaço socialmente construído

Em tese, não há uma concepção específica de desenvolvimento local no PDL; há, antes, uma combinação das diversas políticas urbanas de desenvolvimento local. O que se pode afirmar, então, é que o PDL busca uma concepção de desenvolvimento local sustentável e participativo.

A atenuação dos conflitos sociais e, por conseguinte, os ganhos em termos de justiça social na cidade dependem da efetivação de um planejamento socialmente construído. A intenção do PDL é criar um processo de elaboração, implementação, controle e avaliação do plano 
que seja um exercício coletivo e contínuo de democracia participativa. Cabe salientar que os técnicos tornam-se elementos-chave desse desenvolvimento local, uma vez que se tornam consultores populares.

Por outro lado, o fortalecimento da cidadania requer, segundo a matriz do PDL, uma interação entre o local, o regional e o global, além de buscar a redução das contradições da sociedade. Logo, a sustentabilidade local remete às políticas públicas que não consideram somente a cidade (local), mas estão em sintonia com possíveis alterações no contexto geral. Dessa forma, o plano não pode ter uma finalidade em si, mas precisa esboçar um caminho para possíveis mudanças.

Diante disso, é preciso reconhecer que o reducionismo próprio da idéia de valorização do local pode diminuir as possibilidades dos instrumentos de ação reformista, bem como a democratização da cidade, por meio da inversão de prioridades e da co-gestão com os moradores.

No entanto, é preciso considerar que houve um acréscimo substancial na proposta reformista do PDL, que é o fato de incluir as dimensões do espaço. Dessa maneira, o Riacho Doce poderia ser reconhecido como o produto de um processo histórico de apropriação dos moradores locais por meio da consolidação de representações específicas, que se opõem à reprodução do espaço capitalista.

Enfim, na materialização da idéia de desenvolvimento local, lançase mão de instrumentos que podem ser utilizados no planejamento e na gestão de uma cidade mais justa e eqüitativa, ao mesmo tempo que constituem barreiras, que apenas contribuem para manter a lógica individualista e de mercado.

\section{Avanços e limites do PDL}

A experiência do Riacho Doce foi inegavelmente um avanço significativo em direção a novas alternativas de gestão e planejamento para as áreas de ocupações de Belém. Trata-se de uma ação inovadora em um contexto que dificultava a instalação de uma forma de governo voltada para a reforma urbana. A analise do PDL em si pode não ressaltar os avanços políticos alcançados.

A prefeitura municipal buscou romper com um modelo de planejamento convencional. Para tanto, associou a idéia de construir uma outra matriz de planejamento e de (re) orientar os arranjos institucionais locais ao compromisso de criar uma nova identidade política, econômica e socio-cultural na cidade.

Isso representa uma mudança qualitativa na intervenção urbana em Belém, passando-se do planejamento físico-territorial para o planejamento reformista e politizado. As metas eram a inclusão social dos moradores, a regularização fundiária, a redistribuição dos equipamentos urbanos, o controle e a educação ambiental, a geração de trabalho e de renda e o fortalecimento político dos moradores atingidos.

Ademais, o desenvolvimento urbano ganha outro sentido no PDL: o respeito às especificidades e representações simbólicas dos moradores 
do Riacho Doce. Trata-se de uma concepção de vanguarda que busca incorporar o espaço social ao processo; desse modo, passa-se a servir e a dar sentido à luta pelo direito à cidade, no sentido de Lefebvre (1981).

Por sua vez, a idéia de sustentabilidade não se limita aos impactos ambientais; adota três perspectivas distintas, porém, não excludentes. A noção ambientalista do PDL insere-se em uma ecologia política (COELHO, 2001), que busca conciliar a preservação da área com o fortalecimento econômico e social dos moradores.

A intenção de institucionalizar esses padrões alternativos de gestão e de planejamento para orientar as intervenções urbanas em Belém faz parte da concepção de sustentabilidade política do PDL. Trabalha-se com o amadurecimento do cidadão, por meio da participação efetiva dos atores locais nas várias etapas do projeto.

Por último, a sustentabilidade cultural cria um modelo de ação que procura valorizar as singularidades locais expressas nas práticas espaciais do Riacho Doce. Trata-se de uma tentativa de revelar as diferenças, o uso, em uma linguagem cultural.

A gestão participativa insere o PDL nas premissas do ideário da reforma urbana. No entanto, é preciso considerar que houve um acréscimo substancial na teoria democrática do PDL, que é o fato de incluir a dimensão espacial. Dessa maneira, consideram-se as práticas socio-espaciais, indispensáveis para a melhoria da qualidade de vida, uma vez que se referem ao sentimento de apropriação do espaço.

Porém, entre a concepção adotada no PDL e a execução do projeto, houve desencontros, assinalados por Marques (2001) no Projeto de Recuperação e Urbanização da Bacia do Tucunduba (PRUBT). Um dos problemas está na capacidade de assimilação das idéias assumidas no projeto e no equilíbrio na distribuição da equipe de trabalho. No caso do PDL essas questõess também eram essenciais.

Por outro lado, a associação entre um projeto essencialmente de saneamento ambiental e uma política socio-cultural acabou criando algumas contradições. Por exemplo, a obra de pavimentação da parte leste do Riacho Doce implantou subdivisões espaciais, que repercutiram negativamente na ocupação.

O projeto de remanejamento, outrossim, demonstrou que essa justaposição criou outros descompassos sérios. A remoção, feita pelo PRUBT, até de moradores do Riacho Doce que residiam às margens do igarapé do Tucunduba, excluiu-os dos possíveis ganhos no local. Esse tipo de procedimento acaba induzindo os moradores a buscar uma nova ocupação urbana, além de desarticular as vivências dos moradores remanescentes que possuíam alguma relação com os remanejados.

A dificuldade para garantir a permanência nas proximidades do Riacho Doce levou a equipe técnica a recorrer à prática de indenizar, sem se responsabilizar pela alocação do morador. Além disso, as contingências e a insegurança acabaram favorecendo a especulação imobiliária no local . 
Contudo, o PDL avança ao tentar unir o projeto de fortalecimento da consciência política dos moradores locais ao plano de organização e de reestruturação espacial, envolvendo as lideranças. A inserção de lideranças informais no processo também pode ser considerada um ponto positivo e válido; por contribuir para uma maior organização da comunidade e, por conseguinte, melhorar o desempenho da própria PMB.

A predisposição do PDL para realizar de fato o controle social do projeto baseou-se na democratização das informações sobre a política de intervenção a ser realizada e a capacitação "pedagógica" dos líderes locais. A intenção era incentivar essas lideranças a participar do exercício de co-gestão, fortalecendo sua responsabilidade na comunidade e na entidade que representam.

A instalação da base física do PDL no próprio local de intervenção também ocasionou uma alteração expressiva nos mecanismos de comunicação segundo o formato de gestão democrática. A presença diária dos técnicos possibilitou que os moradores dispusessem de um canal direto para tirar suas dúvidas. Tal estratégia de democratização das informações representa um progresso em direção ao fortalecimento da cidadania.

Na prática, porém, houve uma ambigüidade dentro do PDL em relação ao grau de participação dos moradores do Riacho Doce, visto que o compromisso com a gestão participativa não foi plenamente assumido pela equipe de trabalho, dando margem à constituição de formas de participação incompleta.

As constantes mudanças no projeto habitacional expressam bem essa dinâmica. A cada alteração de tamanho, de forma e de localização das unidades habitacionais efetuadas no PDL, era preciso renovar o termo de adesão, o que era feito por meio do convencimento prévio das lideranças locais, e não por meio de uma negociação com os moradores.

A instauração do diálogo entre a equipe do PDL e as lideranças do Riacho Doce, sustenta-se na idéia de incorporação do conhecimento do "outro" às ações de quem planeja. A questão é que existem formas de compartilhar opiniões que podem levar a um consenso.

Ademais, o trabalho de mobilização social circunscrito às lideranças formais e informais, de certa maneira, pode reservar a esses representantes o papel de porta- vozes junto aos técnicos. Para Souza (2002), tal metodologia de participação suscita uma desigualdade nas reivindicações dentro da própria comunidade e, portanto, nos ganhos, criando uma "sub-representação" política.

Desse modo, haverá sempre o risco de se criarem grupos políticos privilegiados dentro da comunidade, o que é perigoso em uma gestão democrática. Além disso, a qualidade da informação depende da fonte e da intenção dessa fonte, ou seja, a informação não deve ser unilateral, ligada direta ou indiretamente à PMB. Há necessidade de se disponibilizar outras formas de comunicação; caso contrário, o controle social denotará um controle ideológico das famílias locais e de suas necessidades.

O ideal seria que houvesse um canal permanente e democrático 
de negociação e de exercício de cidadania, que permitiria que instituições públicas, porém não "governamentais", a comunidade local e a sociedade em geral, pudessem opinar e, se fosse o caso, criticar a atuação do poder público, para que outras fontes de informação, que conotariam melhor esse controle social.

Por sua vez, a proposta de resgatar as lutas históricas, as identidades culturais e as referências imaginárias dos moradores, para o fortalecimento do espaço social, torna o PDL do Riacho Doce uma alternativa singular de planejamento e de gestão no Brasil. Ao fomentar tais dimensões espaciais essa experiência comprova que é possível conceber uma utopia urbana por meio da inserção do espaço vivido.

A importância do espaço social, como atributo de um desenvolvimento urbano mais humanizado e eqüitativo, tem sido sistematicamente negligenciada por técnicos e pesquisadores. Essa negligência, de acordo com Souza (2002), pode ser considerada mais um dos vícios epistemológicos do urbanismo, que deturpa o significado de qualidade de vida e de justiça social.

Nesse cenário, a equipe de trabalho do PDL buscou incorporar as representações simbólicas por meio da configuração socio-espacial preestabelecida no Riacho Doce. Com isso, tais representações foram definidas como sendo um reflexo das experiências adquiridas no modo de vida anterior.

Assim, as práticas materiais percebidas no Riacho Doce pela equipe de trabalho estão ligadas às encontradas em localidades ribeirinhas da região amazônica. Embora as experiências adquiridas façam parte do cotidiano da ocupação, é preciso considerar que cada espaço cria uma resposta individual com base em suas vivências sociais.

Desse modo, o Riacho Doce é único. O seu cotidiano tem especificidades que resultam da experiência anterior dos seus moradores, incluindo dos ribeirinhos, porém também se redefine a partir das vivências atuais, da relação com a forma metropolitana. As singularidades reais podem ou não representar um simulacro, mas é necessário evitar o equivoco de concebê-las como uma reprodução simbólica do espaço ribeirinho.

Houve uma incorporação dessas representações, mas com modificações, transformações e simulações sem o devido cuidado. É preciso, antes de tudo, analisar as vivências e experiências dos moradores locais com o objetivo de assimilar o cotidiano para, então, formular estratégias espaciais baseadas nas singularidades observadas.

Com isso o processo de (re) organização simbólica do espaço, por meio, por exemplo, da substituição das ruas cujos os nomes foram atribuídos pelos moradores por quadras numeradas, a fim de melhorar o sistema viário e o abastecimento de água, contrapõe-se à idéia de respeito às representações e às lutas históricas do local.

Outra dificuldade da equipe técnica deveu-se à subordinação do projeto socio-ambiental, que no PDL sempre foi o objetivo central, mas, 
na prática, tornou-se dependente do projeto de urbanização. As preocupações excessivas com os "entraves" provocados pelas obras físicas acabaram alterando a própria concepção original de desenvolvimento local para o Riacho Doce.

Na opinião da equipe de trabalho, ainda que os moradores também repetissem o mesmo discurso, os obstáculos principais para a implementação do PDL estavam direta ou indiretamente associados ao projeto físico: a demora na definição do projeto de remanejamento, a perda do terreno dos servidores, a verticalização das unidades habitacionais, a redefinição de custos e a exigência do termo de adesão dos moradores, e o incêndio na ocupação (OLIVEIRA; OLIVEIRA, 2004).

Em razão desses problemas, a proposta de sustentabilidade política, baseada no fortalecimento da cidadania dos moradores ficou comprometida e incompleta. Além disso, à proporção inversa que aumentavam os entraves, diminuía o grau de participação dos moradores no processo de decisões.

É possível discernir as razões da não mobilização dos moradores do Riacho Doce após as modificações negativas feitas pela nova administração municipal, que assumiu em 2005. Contudo, foi também limitada a capacidade de atuação dos moradores como co-gestores da cidade.

O exercício do poder popular na tomada de decisão depende de uma virtuosidade social que não condiz com a realidade dos espaços urbanos, repletos de conflitos e intolerâncias. Para Habermas (1995), o Estado ainda está preso à pressão e às demandas dos grupos sociais com maior poder de barganha política. Por isso, os mecanismos de mobilização social precisam ser reforçados na construção teórica e prática de uma política participativa.

Ademais, a ausência de um debate mais profundo sobre os processos e as estruturas que causam as desigualdades na cidade prejudica a consolidação de espaços públicos de negociação. A justiça social, assim como a noção de democracia participativa, ainda está presa à racionalidade capitalista, cuja lógica não parece oportuna para estabelecer um acesso eqüitativo e justo às tomadas de decisão.

Cabe citar outros tipos de "entraves" a serem superados no contexto urbano. Algumas vezes, argumentos teóricos contestadores dos instrumentos democráticos e participativos escamoteiam interesses de grupos bem definidos. Há uma manipulação do senso comum, por meio de uma propaganda ideológica que algumas vezes repercute nos próprios técnicos e nos pesquisadores.

Aos moradores do Riacho Doce faltou uma mobilização maior para reivindicar a institucionalização de todas as linhas de trabalho assumidas no PDL. O ativismo local, tão marcante na luta pelo direito à moradia, não se fortaleceu com a possibilidade de gerir os serviços públicos na ocupação. Ora, sem a participação efetiva dos atores sociais locais não há uma mudança nesse quadro.

Outra questão importante a ser reconhecida é a limitação do 
planejamento local para promover um processo de desenvolvimento de forma endógena. Em outras palavras, os problemas das ocupações não se resolvem apenas no local, é preciso pensar na estrutura macro.

É o caso de se destacar que, assim como tinha ocorrido no PRUBT, as normas e as exigências do programa Habitar Brasil (HBB), financiado pelo Banco Interamericano de Desenvolvimento (BID), que segue uma linha de raciocínio ligada ao planejamento estratégico, bem como as interpretações distintas dessas normas pelos diversos atores envolvidos, influíram no processo de execução.

A ordem distante é, nesse caso, materializada por essas normas e coerções das agências de financiamento e de controle do PDL. Como foi visto anteriormente, Braga (1999) considera uma ilusão vender a idéia de desenvolvimento micro diante de uma realidade dominada por uma representação mundial: o mercado.

Trata-se, então, de criar um desenvolvimento local e, ao mesmo tempo, sistêmico, que procure redefinir a noção de solidariedade e de integração por meio da cooperação entre as localidades e destas com o global.

Todavia, é necessário ter cuidado com a noção de solidariedade local. Segundo Braga (1999), solidariedade pressupõe universalização, o que torna difícil sua realização de forma localizada. A exposição de uma imagem de solidariedade entre os agentes sociais do Riacho Doce pode estimular um sentimento de fragmentação espacial, distorcendo as diretrizes do PDL.

Já os obstáculos institucionais indicam que ainda faltam alguns ajustes para respaldar a gestão participativa, que exige a institucionalização do PDU de Belém e a valorização do poder legislativo. Há ainda o fator socio-político, que envolve a formação de determinados enclaves territoriais, produto da própria realidade injusta das cidades brasileiras.

Não se trata, então, somente de se explorar as experiências e as vivências dos moradores de cada local. Em que pese o reconhecimento das representações simbólicas, existe a necessidade de introduzir as reais dimensões socio-espaciais próprias do conceito de desenvolvimento.

No entanto, é preciso lembrar que, assim como o espaço, os padrões institucionais e as ações da sociedade também são criações sociais; logo, são sujeitos a rupturas, por meio de insurreições no uso. Portanto, o PDL tem um último mérito o de ser uma fonte concreta de aprendizado para a efetivação de políticas urbanas públicas democráticas e participativas em Belém.

\section{Considerações finais}

A intervenção do poder público nas ocupações urbanas traz uma resposta aos anseios de inúmeras famílias, há muito carentes de infraestrutura urbana. Essa mesma ação pode criar novas expectativas econômicas, sociais e espaciais para a área, que, no final, nem sempre representam uma mudança positiva para a maioria. 
O desenvolvimento local implementado na experiência do Riacho Doce buscou uma reorientação das políticas urbanas em Belém, unindo, em seus objetivos, as idéias de sustentabilidade cultural, política, ambiental e econômica. Assim, não existiu um parâmetro exclusivo, houve, antes, um conjunto de modelos que vão desde uma estratégia competitiva até um modelo de cunho reformista e solidário.

Desse modo, o PDL do Riacho possibilitou, de fato, no contexto das intervenções urbanas recentes em Belém, uma inovação positiva em direção ao planejamento e à gestão democrática e participativa. No entanto, assim como o PDL resulta da combinação de diversas propostas de desenvolvimento local-urbano, o projeto acabou reproduzindo algumas limitações de cada uma delas.

O desenvolvimento socio-espacial é apontado por Souza (2002) como uma alternativa de mudança, tanto no âmbito social quanto no espaço; porém para que esse modelo se materialize, é preciso uma melhoria na qualidade de vida e na justiça social. Na prática, isso depende da autonomia e da capacidade do morador para estabelecer metas e do grau de liberdade dos instrumentos participativos.

Esta opinião vai ao encontro da posição assumida pelo então prefeito de Belém Edmilson Rodrigues, em sua analise da organização social da cidade nas últimas décadas. Para Edmilson Rodrigues (1996) é importante que se discutam mecanismos de pressão e de controle popular para o êxito social da intervenção pública.

Contudo, se o Estado ou o mercado assumem direta ou indiretamente as rédeas da intervenção, há uma grande possibilidade de que esta intervenção seja apartada dos moradores locais, causando novas desigualdades socio-espaciais (RODRIGUES, 1996). Em suma, a autonomia e a liberdade da participação popular revelam o quanto o planejamento e a gestão valorizam os interesses dos moradores atingidos.

A questão exige a inclusão do espaço, e tudo o que este representa para o morador e suas relações na ocupação urbana. O Riacho Doce, visto como um lugar, apresenta resíduos de temporalidades outras que coexistem com o moderno, permitindo que se perceba a resistência de determinados usos e conteúdos não capitalistas.

Dessa forma, a ocupação urbana do Riacho Doce abrange em seu cotidiano comportamentos variados, produto das experiências e vivências das famílias que lá vivem. Logo, o PDL teve a oportunidade de incorporar o vivido por meio das representações sociais do lugar, definindo um desenvolvimento cada vez mais humano e eqüitativo.

Este trabalho buscou rever a contribuição teórica e conceitual da teoria social e crítica sobre o espaço, o planejamento e o desenvolvimento urbano. Constata-se que a relação do indivíduo com o seu meio tem de levar em consideração o vivido, o uso, enfim, o lugar tem de ser (re)apropriado por todos aqueles que estudam o espaço social.

Este posicionamento contrapõe-se ao espaço abstrato, afastado da realidade, concebido com o objetivo único de padronizar e regular o 
cotidiano das cidades. Daí a importância teórica de ensinamentos como os de Lefebvre (1974), que tratou o tema em diversas obras, buscando, no direito à cidade, o direito à liberdade, à individualidade, ao conflito, à solidariedade, ao lazer enfim à vida.

Mais do que expor uma inquietação teórica ou fazer um exercício de crítica, buscou-se aqui analisar a intervenção no Riacho Doce, durante o governo do Partido dos Trabalhadores, como uma experiência que representa verdadeiramente uma primeira grande conquista em relação à concepção e à prática de um planejamento e de uma gestão democrática em Belém.

Trata-se de um instrumento que pode concorrer de forma efetiva para a concretização de um desenvolvimento urbano alternativo. O desafio está em executar ações que possam considerar as redes de ação em torno do espaço, assegurando que a maioria possa participar efetivamente do processo de decisões.

Entretanto, as alterações na execução do PDL ocorridas logo após a posse da nova administração municipal de Belém em 2005 mostram que a institucionalização de políticas alternativas para a cidade ainda fraqueja diante de uma racionalidade abstrata dos técnicos, enquanto a ausência de autonomia e de liberdade nos mecanismos de participação não despertou uma "cidadania ativa" entre os moradores do Riacho Doce.

Com base nessa experiência, pode-se afirmar que é necessário (re)pensar os mecanismos de participação popular nas ocupações urbanas para dar aos moradores a oportunidade de retomar a direção do seu próprio desenvolvimento, construindo-se, assim, uma proposta mais justa, mesmo no âmbito de uma sociedade capitalista, cada vez mais contraditória e excludente.

Importa pensar em uma política de desenvolvimento urbano que (re) aproxime definitivamente as vivências e as experiências singulares, na qual o morador envolvido tenha a liberdade e a autonomia de desempenhar o seu papel de co-gestor, implantando uma nova forma de organização espacial no contexto urbano, que beneficiaria a sociedade como um todo.

Enfim, o desenvolvimento a partir de cada lugar não significa somente uma mera retórica conceitual, que se contrapõe aos diversos modelos de desenvolvimento local. O lugar pode ser um contraponto ao espaço padronizado e, como tal, torna-se imprescindível para combater o repetitivo e o homogêneo.

Portanto, é imprescindível que as diversas expressões de resistência, cristalizadas no cotidiano dos lugares, sejam valorizadas e aproveitadas pela intervenção pública. Podem não representar uma transformação imediata no sistema como um todo, entretanto, graças aos elementos desses universos singulares, ligados à totalidade, podemos apreender os tempos e os espaços, refazendo, a cada momento, os caminhos aparentemente já definidos pela história. 


\section{REFERÊNCIAS}

BELÉM. Prefeitura Municipal. Secretaria Municipal de Coordenação Geral do Planejamento e da Gestão. Plano de desenvolvimento local Riacho Doce e Pantanal. Belém, 2001a, v. 1.

BELÉM. Prefeitura Municipal. Secretaria Municipal de Coordenação Geral do Planejamento e da Gestão. Plano de desenvolvimento local Riacho Doce e Pantanal. Belém, 2001b, v. 4.

BRAGA, Tânia M. Desenvolvimento local endógeno e suas implicações na formulação de políticas municipais: Descentralização/ Participação ou Fragmentação/Estratégias de legitimação. Porto Alegre: ANPUR, 1999.

CARLOS, Ana Fani Alessandri. O lugar no/do mundo. São Paulo: Hucitec, 1996.

COELHO, Maria Célia N. Impactos ambientais em áreas urbanasTeroias, Conceitos e métodos de pesquisa. In: GUERRA, Antonio José T.; CUNHA, Sandra Baptista. Impactos ambientais urbanos no Brasil. Rio de janeiro: Bertrand Brasil, 2001.

COSTA, Solange M. Gayoso da. Razões ou ilusões de estabilidade: representações e referências imaginárias sobre a habitação na "ocupação espontânea" Riacho Doce-Belém-Pará. 2002. Dissertação (Mestrado em Sociologia) - Universidade Federal do Pará, Belém, 2002.

FRANCO, Augusto di. Porque precisamos de desenvolvimento local integrado e sustentável. Brasília, DF: Millennium, 2000.

FREY, Klaus. Crise do Estado e estilos de gestão municipal. Revista Lua Nova, São Paulo, n. 37, p. 107-138, 1996.

HABERMAS, J. Três modelos normativos de democracia. Revista Lua Nova, São Paulo, n. 36, p. 39-53, 1995.

LEFEBVRE, Henri. La production de l'espace. Paris: Anthropes, 1974.

MARQUES, Maria Amélia da Silva P. Panejamento e gestão urbana no município de Belém (1997-2000): Práticas e representações sobre a política de saneamento ambiental a partir da experiência de intervenção na bacia do Tucunduba. Dissertação (Mestrado em Planejamento do Desenvolvimento). NAEA/UFPA. Belém, 2001. 
MATUS, Carlos. Adeus senhor presidente: planejamento, antiplanejamento e governo. Recife: Litteris, 1989.

OLIVEIRA, Maria Claudia Zaidan de; OLIVEIRA, Sandra Ikikame de. Entraves e obstáculos acerca da implantação urbanística: a experiência do Plano de Desenvolvimento Local do Riacho Doce e Pantanal. Trabalho de conclusão de curso. CA/UFPA, 2004.

RODRIGUES, Edmilson Brito. Aventura urbana. Urbanização, trabalho e meio ambiente em Belém. Belém: NAEA/UFPA, 1996.

SANCHES, Fernanda. Políticas urbanas em renovação: uma releitura crítica dos modelos emergentes. Rio de Janeiro: IPPUR, 1999.

SANTOS, Milton. A natureza do espaço: técnica e tempo razão e emoção. São Paulo: HUCITEC, 2002.

SOUZA, Marcelo Lopes de. Mudar a cidade: uma introdução crítica ao planejamento e à gestão urbanos. Rio de janeiro: Bertrand Brasil, 2002.

TRINDADE JR, Saint Clair Cordeiro da. Belém: Forma metropolitana e cotidianidade na Amazônia brasileira. Revista Humanitas, Belém, v. 15, n. 2, p. 143-158, 1999. 